\title{
Suicides Among Incarcerated Persons in 18 U.S. States: Findings From the National Violent Death Reporting System, 2003-20I4
}

Journal of Correctional Health Care 2020, Vol. 26(3) 279-29

(c) The Author(s) 2020

Article reuse guidelines: sagepub.com/journals-permissions DOI: $10.1177 / 10783458209395 / 2$ journals.sagepub.com/home/jcx

(SAGE

\author{
Kristiana J. Dixon, PhD' $^{\circledR}$, Allison M. Ertl, PhD', \\ Rachel A. Leavitt, MPH', Kameron J. Sheats, PhD', \\ Katherine A. Fowler, PhD', and Shane P. D. Jack, PhD'
}

\begin{abstract}
Using data from the National Violent Death Reporting System (2003-20I4), this study examined the characteristics and contributing circumstances of suicides in correctional facilities. $\chi^{2}$ and logistic regression analyses revealed that, compared to nonincarcerated suicide decedents, incarcerated suicide decedents had significantly lower odds of positive toxicology for substances but significantly higher odds of substance abuse problems. Descriptive subanalyses indicated that incarcerated suicide decedents often were incarcerated for personal crimes. They often died $\leq$ I week of incarceration, in a cell (frequently single-person or segregation), by hanging, using bedding material. Positive toxicology was more common for incarcerated decedents who died shortly after versus later in their incarceration. Findings highlight the need for enhanced detection and treatment of suicidal behavior, especially during early and vulnerable periods of incarceration.
\end{abstract}

\section{Keywords}

suicide, incarceration, inmate, jail, prison

Suicide rates are higher among incarcerated than nonincarcerated persons (Konrad et al., 2007; Snow et al., 2002). In 2014, the suicide rate was 50 per 100,000 jail inmates (Noonan, 2016a), 20 per 100,000 state prisoners, and 14 per 100,000 federal prisoners (Noonan, 2016b), while the ageadjusted suicide rate for the entire U.S. population was 12.9 per 100,000 (Centers for Disease Control and Prevention [CDC], 2017).

\footnotetext{
'Division of Violence Prevention, National Center for Injury Prevention and Control, Centers for Disease Control and Prevention, Atlanta, GA, USA

Corresponding Author:

Allison Ertl, PhD, Division of Violence Prevention, Centers for Disease Control and Prevention, 4770 Buford Hwy, MS F-63, Atlanta, GA 3034I, USA.

Email: moq4@cdc.gov
} 
Several factors may contribute to increased rates of suicide for incarcerated individuals, including personal and life circumstances, the incarceration process, and the correctional environment (World Health Organization [WHO], 2007). Many incarcerated individuals are more vulnerable to suicide even prior entering the correctional system due to previous suicidal thoughts and behavior, mental illness, substance use problems, and/or economic and social disenfranchisement (Blaauw et al., 2005; WHO, 2007). Other individual-level factors that have been associated with suicides among incarcerated persons include first incarceration, being male, being White, and young age (Cramer et al., 2017).

However, the incarceration process also may elevate the likelihood of suicidal behavior due to accompanying stressors such as loss of autonomy and freedom, reduced social (family and friends) and financial support, substance withdrawal, and feelings of hopelessness, shame, and embarrassment (Cramer et al., 2017; WHO, 2007). Stress associated with legal aspects of incarceration (e.g., sentence length) and facing the reality of incarceration also may increase inmates' vulnerability for suicide (Cramer et al., 2017), as research suggests that suicides are more likely to occur during the first few months of incarceration, in close proximity to court hearings, and among those with long sentence lengths (Cramer et al., 2017; Hayes, 2010).

Features of the correctional environment also may affect suicidal behavior, including overcrowded facilities, a combative culture with regular use of force by other inmates and correctional officers, and overworked and undertrained facility staff (Cramer et al., 2017; WHO, 2007). Segregated and single-cell housing can restrict movement and create social isolation that can contribute to psychological deterioration and increased risk of suicide. In addition, individuals in isolated housing often experience other risk factors for suicide, such as new disciplinary charges, reduced privileges, psychological distress, and medical and psychiatric conditions (Reeves \& Tamburello, 2014). Inadequate or limited access to health and mental health services and a shortage of sufficiently trained mental health practitioners also may contribute to increased vulnerability for suicide among inmates due to reduced availability of mental health treatment and suicide prevention services (Cramer et al., 2017).

This study aimed to identify circumstances and characteristics of suicides among incarcerated persons and compare them with suicides of nonincarcerated persons to identify factors unique to this population, all of which can guide suicide prevention efforts in correctional settings.

\section{Method}

\section{Data Source}

Data came from CDC's National Violent Death Reporting System (NVDRS), a state-based, active surveillance system that collects detailed information on all violent deaths (including suicides) occurring in participating states. NVDRS collates data from death certificates, law enforcement reports, and coroner/medical examiner records. Trained data abstractors extract information on the characteristics and circumstances of these deaths using standardized CDC protocols and write narratives that provide a descriptive summary of events preceding the death (Blair et al., 2016).

\section{Case Selection and Narrative Coding}

Cases included all suicide decedents from the 18 states that participated in NVDRS during 2003$2014^{1}$ where the decedent was $\geq 10$ years of age. Incarcerated suicide decedents included all individuals detained at a law enforcement or correctional facility when fatally injured. Suicide decedents were not considered incarcerated if under arrest but not detained, on community supervision, residing at a halfway house or detoxification facility, or off-site on work release when fatally injured. 
For all incarcerated suicide cases, the authors coded case narratives for additional variables, including (a) special housing assignment (e.g., segregation, medical or mental health unit), (b) single-person cell (no cellmates; yes/no), (c) facility location where fatally injured (e.g., cell, bathroom), (d) ligature mechanism (when applicable; e.g., bedding, clothing), (e) anchoring location or device (when applicable; e.g., bed, door), (f) criminal charge(s) or offense(s) (e.g., personal, property), (g) length of time incarcerated for current offense(s) when fatally injured (e.g., $\leq 1$ day, 2 to 7 days, 8 days to 1 month), and (h) upcoming release ${ }^{2}$ (yes/no). The authors coded 200 initial case narratives to assess pairwise inter-rater reliability, ranging from $\kappa=0.66$ (single-person cell) to $\kappa=1.00$ (upcoming release). Coding discrepancies were resolved by group discussion. The remaining cases were divided among the authors and coded independently. When unsure about coding decisions, final determinations were made by the first author or through coauthor group discussion.

\section{Statistical Analysis}

Demographics, incident characteristics, and precipitating circumstances were examined by incarceration status (incarcerated vs. nonincarcerated) using $\chi^{2}$ tests. Significant results were examined further using logistic regression, controlling for age, sex, and race/ethnicity. A descriptive subanalysis of incarcerated suicides was conducted with the additional variables coded from case narratives.

\section{Results}

\section{Incarcerated Versus Nonincarcerated Suicide Decedents}

There were 1,896 incarcerated suicide decedents and 121,512 nonincarcerated suicide decedents (Table 1). Incarcerated decedents were significantly younger than nonincarcerated decedents at the time of death; the largest proportion (44.4\%) of incarcerated decedents was aged 25 to 39 years, whereas the largest proportion $(41.2 \%)$ of nonincarcerated decedents was aged 40 to 59 years. Although the majority of both incarcerated and nonincarcerated decedents was male $(91.2 \%$ and $77.9 \%$, respectively), a significantly higher proportion of incarcerated decedents was male. Incarcerated decedents were significantly more likely to be racial/ethnic minorities; $33.8 \%$ of incarcerated decedents were racial/ethnic minorities (non-Hispanic, Black $=17.6 \%$; Hispanic $=$ $10.1 \%$; non-Hispanic, other $=6.1 \%$ ) versus $15.3 \%$ of nonincarcerated decedents (non-Hispanic, Black $=6.3 \%$; Hispanic $=4.5 \%$; non-Hispanic, other $=4.5 \%)$. Incarcerated decedents had half the odds of being married or in a civil union as compared with nonincarcerated decedents $(p<.05$, adjusted odds ratio $[\mathrm{aOR}]=0.52 ; \mathrm{CI}[0.46,0.59])$. The mechanism of fatal injury for the majority $(52.5 \%)$ of nonincarcerated decedents was a firearm, whereas $92.2 \%$ of incarcerated decedents died by asphyxiation, with over 33 times the odds of dying by this mechanism $(p<.05$, $\mathrm{aOR}=33.02$; CI $[27.85,39.14])$.

Circumstance information was known for $90.0 \%$ of incarcerated and $89.3 \%$ of nonincarcerated suicides. Intimate partner problems had significantly lower odds of being noted for incarcerated than nonincarcerated suicide decedents $(\mathrm{aOR}=0.25$; CI $[0.22,0.29])$. Incarcerated decedents had significantly higher odds of having perpetrated violence in the past month $(\mathrm{aOR}=1.29$; CI $[1.07,1.54])$ and to have contributing criminal legal problems ( $\mathrm{aOR}=14.63$; CI $[13.19,16.24])$ compared with nonincarcerated decedents. Suicides of incarcerated persons had significantly higher odds of being related to a serious crime (e.g., robbery; $\mathrm{aOR}=2.13$; CI $[1.72,2.65]$ ), which may or may not have been the crime for which they were incarcerated.

Current diagnosed mental health problems overall (aOR $=0.74$; CI $[0.67,0.82])$, a diagnosis of depression $(\mathrm{aOR}=0.53$; CI [0.47, 0.60]), current depressed mood $(\mathrm{aOR}=0.36$; $\mathrm{CI}[0.32,0.41])$, and alcohol problems $(\mathrm{aOR}=0.49$; CI $[0.42,0.57])$ were significantly less likely to be reported 
Table I. Characteristics of Incarcerated Versus Nonincarcerated Suicide Decedents.

\begin{tabular}{|c|c|c|c|c|}
\hline \multirow[b]{3}{*}{ Characteristic or Circumstance } & Incarcerated & Nonincarcerated & \multirow[b]{3}{*}{$\chi^{2}$} & \multirow[b]{3}{*}{ aOR $(95 \% \mathrm{Cl})$} \\
\hline & $n=1,896$ & $n=121,512$ & & \\
\hline & $n(\%)$ & $n(\%)$ & & \\
\hline Age group (years) & $1,895^{\mathrm{a}}$ & $121,354^{\mathrm{a}}$ & & \\
\hline 10 to 17 & $21(1.1)$ & $3,627(3.0)$ & $23.0 *$ & \\
\hline 18 to 24 & 324 (17.1) & $12,406(10.2)$ & $95.2^{*}$ & \\
\hline 25 to 39 & $842(44.4)$ & $28,903(23.8)$ & $433.1^{*}$ & \\
\hline 40 to 59 & $660(34.8)$ & $49,948(4 \mid .2)$ & $30.9 *$ & \\
\hline $60+$ & $48(2.5)$ & $26,470(21.8)$ & $410.7^{*}$ & \\
\hline Sex & $1,896^{\mathrm{a}}$ & $121,455^{\mathrm{a}}$ & $195.5^{*}$ & \\
\hline Male & $1,730(9 \mid .2)$ & $94,553(77.9)$ & & \\
\hline Female & $166(8.8)$ & $26,902(22.1)$ & & \\
\hline Race/ethnicity & $1,895^{\mathrm{a}}$ & $121,273^{\mathrm{a}}$ & & \\
\hline Non-Hispanic, White & $1,256(66.3)$ & $102,730(84.7)$ & $482.0 *$ & \\
\hline Non-Hispanic, Black & $333(17.6)$ & $7,615(6.3)$ & $394.2^{*}$ & \\
\hline Hispanic & $191(10.1)$ & $5,442(4.5)$ & $133.7^{*}$ & \\
\hline Non-Hispanic, other & $115(6.1)$ & $5,486(4.5)$ & $10.3 *$ & \\
\hline Marital status ${ }^{\mathrm{b}}$ & $1,836^{\mathrm{a}}$ & $119,825^{a}$ & $225.2^{*}$ & $0.52(0.46,0.59)$ \\
\hline Married/civil union & $355(19.3)$ & $43,467(36.3)$ & & \\
\hline Not married & $\mathrm{I}, 48 \mathrm{I}(80.7)$ & $76,358(63.7)$ & & \\
\hline Never married & $972(52.9)$ & $38,537(32.2)$ & & \\
\hline Widowed & $52(2.8)$ & $7,429(6.2)$ & & \\
\hline Divorced & $400(21.8)$ & $26,665(22.3)$ & & \\
\hline Other & $57(3.1)$ & $3,727(3.1)$ & & \\
\hline Mechanism & $1,892^{\mathrm{a}}$ & $120,527^{\mathrm{a}}$ & & \\
\hline Firearm ${ }^{c}$ & I $(0.1)$ & $63,324(52.5)$ & $2,055.1 *$ & \\
\hline Asphyxiation & $1,745(92.2)$ & $28,342(23.5)$ & 4,744.9* & $33.02(27.85,39.14)$ \\
\hline Sharp instrument & $5 I(2.7)$ & $2,229(1.9)$ & $7.3^{*}$ & $1.57(1.18,2.07)$ \\
\hline Poisoning & $52(2.8)$ & $20,787(17.3)$ & $277.2^{*}$ & $0.18(0.13,0.24)$ \\
\hline Fall & $34(1.8)$ & $2,171(1.8)$ & 0.0 & \\
\hline Other ${ }^{c}$ & $9(0.5)$ & $3,674(3.1)$ & $42.2^{*}$ & \\
\hline Cases with known circumstances & $1,706(90.0)$ & $108,521(89.3)$ & & \\
\hline \multicolumn{5}{|l|}{ Interpersonal relationships } \\
\hline Intimate partner problem & $242(14.2)$ & $33,299(30.7)$ & $216.0^{*}$ & $0.25(0.22,0.29)$ \\
\hline Perpetrator of violence in the past month & $133(7.8)$ & $4,296(4.0)$ & $64.1 *$ & $1.29(1.07,1.54)$ \\
\hline \multicolumn{5}{|l|}{ Life circumstances } \\
\hline Criminal legal problem & I,II5 (65.4) & $9,613(8.9)$ & $6,102.8^{*}$ & $14.63(13.19,16.24)$ \\
\hline Precipitated by a serious crime & $95(5.6)$ & $1,9 \mid 4(1.8)$ & 135.9* & $2.13(1.72,2.65)$ \\
\hline \multicolumn{5}{|l|}{ Behavioral health } \\
\hline Current diagnosed MH condition & $577(33.8)$ & $48,809(45.0)$ & $84.5^{*}$ & $0.74(0.67,0.82)$ \\
\hline Depression/dysthymia & $311(18.2)$ & $36,946(34.1)$ & $187.8^{*}$ & $0.53(0.47,0.60)$ \\
\hline Bipolar disorder & $\mathrm{II} \mid(6.5)$ & $7,110(6.6)$ & 0.01 & \\
\hline Schizophrenia & $60(3.5)$ & $2,383(2.2)$ & $13.5^{*}$ & $1.20(0.93,1.57)$ \\
\hline Anxiety & $62(3.6)$ & $5,543(5.1)$ & 7.6* & $0.90(0.70,1.16)$ \\
\hline Other & $91(5.3)$ & $4,950(4.6)$ & 2.3 & \\
\hline Not specified & $117(6.9)$ & $4,542(4.2)$ & $29.6 *$ & $1.69(1.40,2.05)$ \\
\hline Current depressed mood & $324(19.0)$ & $44,719(4 \mid .2)$ & $343.0^{*}$ & $0.36(0.32,0.4 I)$ \\
\hline Alcohol problem & $179(10.5)$ & $19,430(17.9)$ & $63.1^{*}$ & $0.49(0.42,0.57)$ \\
\hline Other substance problem & $350(20.5)$ & $16,286(15.0)$ & $39.8^{*}$ & $1.18(1.05,1.33)$ \\
\hline
\end{tabular}


Table I. (continued)

\begin{tabular}{|c|c|c|c|c|}
\hline \multirow[b]{3}{*}{ Characteristic or Circumstance } & \multirow{2}{*}{$\frac{\text { Incarcerated }}{n=1,896}$} & \multirow{2}{*}{$\frac{\text { Nonincarcerated }}{n=121,512}$} & \multirow[b]{3}{*}{$\chi^{2}$} & \multirow[b]{3}{*}{$\mathrm{aOR}(95 \% \mathrm{Cl})$} \\
\hline & & & & \\
\hline & $n(\%)$ & $n(\%)$ & & \\
\hline Current $\mathrm{MH} / \mathrm{SA}$ treatment & $422(24.7)$ & $35,448(32.7)$ & $48.1^{*}$ & $0.83(0.74,0.93)$ \\
\hline Ever treated for $\mathrm{MH} / \mathrm{SA}$ & $517(30.3)$ & $41,869(38.6)$ & $48.6^{*}$ & $0.82(0.74,0.91)$ \\
\hline Hx of suicidal thoughts ${ }^{d}$ & $83(22.2)$ & $7,901(32.1)$ & $16.7^{*}$ & $0.62(0.48,0.79)$ \\
\hline Hx of suicide attempts & 340 (19.9) & $21,638(19.9)$ & 0.0 & \\
\hline Suicide note & 397 (23.3) & $36,680(33.8)$ & $83.4^{*}$ & $0.70(0.63,0.79)$ \\
\hline Disclosed suicidal intent & $285(16.7)$ & $30,563(28.2)$ & $109.4^{*}$ & $0.50(0.44,0.57)$ \\
\hline \multicolumn{5}{|l|}{ Disclosed to whom ${ }^{\text {d }}$} \\
\hline Previous/current partner & $8(11.0)$ & $3,368(4 \mid .3)$ & & \\
\hline Other family member & $20(27.4)$ & $2,662(32.6)$ & & \\
\hline Health care worker & $2(2.7)$ & $306(3.8)$ & & \\
\hline Friend/colleague & $10(13.7)$ & $1,07 \mid(13.1)$ & & \\
\hline Other ${ }^{\mathrm{e}}$ & $33(45.2)$ & $751(9.2)$ & & \\
\hline \multicolumn{5}{|l|}{ Toxicology ${ }^{f}$} \\
\hline Alcohol & $101(7.1)$ & $27,898(35.8)$ & $500.7 *$ & $0.11(0.09,0.14)$ \\
\hline Marijuana & $74(8.8)$ & 4,689 (II.5) & 6. I* & $0.51(0.40,0.66)$ \\
\hline Cocaine & $48(4.0)$ & $3,715(6.9)$ & $15.8 *$ & $0.37(0.28,0.50)$ \\
\hline Opiates & $98(8.2)$ & $12,196(22.5)$ & $139.7 *$ & $0.41(0.33,0.50)$ \\
\hline
\end{tabular}

Source: NVDRS, 18 U.S. States, 2003-2014.

Note. The aORs for the logistic regression analyses controlled for age group, sex, and race/ethnicity. Percentages may not add to $100 \%$ due to rounding. NVDRS = National Violent Death Reporting System; aOR = adjusted odds ratio; $\mathrm{Cl}=$ confidence interval; $\mathrm{Hx}=$ history; $\mathrm{MH}=$ mental health; $\mathrm{SA}=$ substance abuse.

${ }^{a}$ Number of cases where this information was known. ${ }^{\mathrm{b}}$ Test is between married/civil union and not married. ${ }^{\mathrm{c}}$ Fisher's exact test was conducted. Statistical reliability criteria for logistic regression were not met because cell frequencies were less than the minimum required. "Variable was added to NVDRS in 2013. "For incarcerated decedents, "other" included cellmates, other inmates, correctional officers, facility mental health professionals, other/unspecified correctional staff, police, and the decedent's attorney. For nonincarcerated decedents, "other" included neighbor, health care worker and intimate partner, health care worker and other, and other (unspecified). 'Of decedents who had a known test result, the total number and percentage of suicide decedents that tested positive for each substance. Denominators for each are as follows: I,4I7 incarcerated and 77,95I nonincarcerated suicide decedents had a known test result for alcohol; 846 incarcerated and 40,899 nonincarcerated suicide decedents had a known test result for marijuana; I, I 98 incarcerated and 53,5I 5 nonincarcerated suicide decedents had a known test result for cocaine; I,20I incarcerated and 54,239 nonincarcerated suicide decedents had a known test result for opiates.

$*_{p}<.05$ for $\chi^{2}$ tests.

among incarcerated decedents. However, incarcerated decedents were significantly more likely to have a known diagnosis of schizophrenia $(\mathrm{aOR}=1.20$; CI $[0.93,1.57])$, unspecified mental health diagnosis $(\mathrm{aOR}=1.69$; $\mathrm{CI}[1.40,2.05])$, or a reported substance abuse problem other than alcohol $(\mathrm{aOR}=1.18 ; \mathrm{CI}[1.05,1.33])$. Incarcerated decedents had lower odds of currently $(\mathrm{aOR}=0.83 ; \mathrm{CI}$ $[0.74,0.93])$ or ever $(\mathrm{aOR}=0.82$; CI $[0.74,0.91])$ having received mental health or substance abuse treatment, having a history of suicidal thoughts $(\mathrm{aOR}=0.62$; $\mathrm{CI}[0.48,0.79])$, leaving a suicide note $(\mathrm{aOR}=0.70$; CI $[0.63,0.79])$, or disclosing suicidal intent $(\mathrm{aOR}=0.50$; CI $[0.44,0.57])$. Among incarcerated decedents who disclosed suicidal intent, $45.2 \%$ disclosed to someone in the correctional system, such as a cellmate, another inmate, a correctional officer, or other/unspecified correctional staff, ${ }^{3}$ and $27.4 \%$ disclosed to a family member other than an intimate partner. Incarcerated decedents had significantly lower odds of testing positive for substances at the time of death; $7.1 \%$ tested positive for alcohol, $8.8 \%$ for marijuana, $4.0 \%$ for cocaine, and $8.2 \%$ for opiates. 


\section{Subanalysis of Incarcerated Suicide Decedents}

The vast majority $(92.8 \%)$ of incarcerated suicide decedents were in a cell when fatally injured (Table 2). Among incarcerated decedents, $16.6 \%$ were reportedly housed without a cellmate $(8.2 \%$ were in segregation). ${ }^{4}$ Additionally, $4.4 \%$ of incarcerated decedents were housed in holding or booking cells, $2.3 \%$ in a medical unit, and $1.8 \%$ in a mental health unit. When the length of incarceration was known, $24.1 \%$ were incarcerated for $\leq 24$ hours and $55.5 \%$ were incarcerated for $\leq 1$ week. The largest proportion of fatal injuries occurred between noon and 6 p.m. (31.7\%). When criminal offense(s) that led to incarceration were known, $46.1 \%$ were incarcerated for a personal crime ${ }^{5}$ and $23.4 \%$ for a substance-related crime. Among those incarcerated for a personal crime, $32.1 \%$ were held for assault/battery and $27.6 \%$ for homicide.

The overwhelming majority $(92.2 \%)$ of incarcerated decedents died by asphyxiation (Table 1), mostly by hanging $(97.5 \%)$ (Table 3 ). When the ligature mechanism was known for asphyxia deaths, most $(71.8 \%)$ involved bedding. Of hanging deaths where the anchoring point was known, over one third (35.7\%) attached the ligature to a bed, $82.2 \%$ of which were noted to be bunk beds.

Decedents who died within a week of incarceration tested positive for substances more often than those who died more than a week after incarceration (Table 4). Of decedents known to have died within 24 hours of incarceration who had available toxicology test results, $34.6 \%$ tested positive for alcohol, $23.5 \%$ for marijuana, $11.6 \%$ for cocaine, and $7.3 \%$ for opiates.

\section{Discussion}

Suicide is a concern for incarcerated persons, correctional institutions and staff, and inmates' loved ones. Those with legal responsibility for correctional populations also have a vested interest in ensuring inmates' health and safety, including protection from self-harm, as a failure to do so can expose correctional systems to liability (Konrad et al., 2007; WHO, 2007). The purpose of this analysis was to use a large multistate sample to examine suicides among incarcerated populations to identify characteristics and circumstances that point to opportunities for suicide prevention. The comparison of incarcerated and nonincarcerated suicides provided a point of reference when describing the circumstances surrounding incarcerated suicides.

\section{Incarcerated Versus Nonincarcerated Suicide Decedents}

Incarcerated suicide decedents in this analysis were more likely than nonincarcerated suicide decedents to be young, male, racial/ethnic minorities, and never married. This mirrors the overall prison population in the United States (Carson \& Sabol, 2016), perhaps suggesting that inmate suicides are unrelated to these characteristics. Persons of color are incarcerated disproportionately, possibly due to inequitable arrest and sentencing rates, especially among young, Black males (Mauer \& King, 2007; Spohn, 2013). Incarcerated decedents largely were young and never married, which may be explained by the "aging out" of criminal behavior (Loeber \& Stallings, 2011; Sampson \& Laub, 2003). Finally, incarcerated decedents had higher odds of dying by hanging, whereas nonincarcerated decedents had higher odds of dying by firearm, which points to decedents' access to different lethal means.

Incarcerated decedents were less likely to have a known diagnosed mental health condition than nonincarcerated decedents. This was unexpected given the overall association of mental health conditions with suicide and elevated rates of mental health conditions in incarcerated populations (Al-Rousan et al., 2017; Bronson \& Berzofsky, 2017; James \& Glaze, 2006). A previous study reported that approximately half of the most common mental health conditions (e.g., depression, anxiety) were recognized in the first month of incarceration (Al-Rousan et al., 2017). The majority 
Table 2. Personal and Environmental Characteristics of Incarcerated Suicide Decedents.

\begin{tabular}{|c|c|}
\hline \multirow[b]{3}{*}{ Characteristic } & \multirow{2}{*}{$\begin{array}{c}\text { Incarcerated Suicide Decedents } \\
\qquad n=1,896\end{array}$} \\
\hline & \\
\hline & $n(\%)$ \\
\hline Facility location & $1,553^{\mathrm{a}}$ \\
\hline Cell & $1,44 \mid(92.8)$ \\
\hline Bathroom/shower & $64(4.1)$ \\
\hline Common area & $29(1.9)$ \\
\hline Off-grounds & $5(0.3)$ \\
\hline Other, on-grounds & $14(0.9)$ \\
\hline Special housing & $476^{a}$ \\
\hline Single-person cell (including segregation) & $314(16.6)$ \\
\hline Holding/booking & $84(4.4)$ \\
\hline Medical unit & $44(2.3)$ \\
\hline Mental health unit & $34(1.8)$ \\
\hline Time incarcerated & $669^{\mathrm{a}}$ \\
\hline Recently incarcerated ${ }^{c}$ & $590(88.2)$ \\
\hline I day or less & $161(24.1)$ \\
\hline 2 to 7 days & $210(31.4)$ \\
\hline 8 days to I month & $84(12.6)$ \\
\hline 31 days to 6 months & $81(12.1)$ \\
\hline Unspecified & $54(8.1)$ \\
\hline I8I days to I year & $24(3.6)$ \\
\hline 366 days to 5 years & $27(4.0)$ \\
\hline More than 5 years & $28(4.2)$ \\
\hline Time of injury & $1,066^{\mathrm{a}}$ \\
\hline Morning (6:00 a.m. to II:59 a.m.) & $221(20.7)$ \\
\hline Afternoon (I2:00 p.m. to 5:59 p.m.) & $338(31.7)$ \\
\hline Evening (6:00 p.m. to II:59 p.m.) & $287(26.9)$ \\
\hline Overnight (I2:00 a.m. to 5:59 a.m.) & $220(20.6)$ \\
\hline Offense type & $959^{\mathrm{a}}$ \\
\hline Personal & $442(46.1)$ \\
\hline Homicide & $122(27.6)$ \\
\hline Robbery & $75(17.0)$ \\
\hline Assault/battery & $142(32.1)$ \\
\hline Domestic violence-related assault ${ }^{d}$ & $90(20.4)$ \\
\hline Other ${ }^{\mathrm{e}}$ & $81(18.3)$ \\
\hline Property & $154(16.1)$ \\
\hline Sexual & 147 (I5.3) \\
\hline Substance-related & $224(23.4)$ \\
\hline Other & $232(24.2)$ \\
\hline Upcoming release & $33^{\mathrm{a}}(1.7)$ \\
\hline
\end{tabular}

Source: NVDRS, 18 U.S. States, 2003-2014.

Note. Percentages may not add to 100\% due to rounding. Offense types were not mutually exclusive, so percentages may add to over 100. NVDRS = National Violent Death Reporting System.

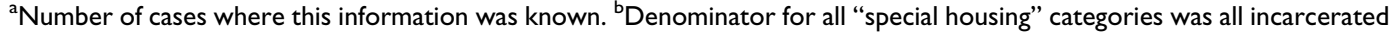
suicide decedents. "Decedents were considered "recently incarcerated" if they were incarcerated for 6 months or less or the narrative stated that the decedent had "recently" been incarcerated or detained. 'Cases were coded as having domestic violence-related crimes if the narrative identified the offense as a domestic violence or intimate partner violence offense or if an offense involved current or former intimate partners. "Crimes in the "other" category included violation of a protective/ restraining order, kidnapping, abduction, false imprisonment, child abuse and neglect, other, unspecified personal crime. 
Table 3. Characteristics of Asphyxia Deaths Among Incarcerated Suicide Decedents.

\begin{tabular}{lc} 
& Incarcerated Asphyxia Suicides \\
\cline { 2 - 2 } Characteristic & $n=1,745$ \\
\hline Method of asphyxia & $n(\%)$ \\
Hanging & \\
Suffocation & $1,701(97.5)$ \\
Strangulation & $21(1.2)$ \\
Unspecified & $21(1.2)$ \\
Ligature mechanism & $2(0.1)$ \\
Bedding & $1,218^{\mathrm{a}}$ \\
Clothing & $875(71.8)$ \\
Clothing accessories & $132(10.8)$ \\
Towels/rags & $79(6.5)$ \\
Cords & $40(3.3)$ \\
Other & $50(4.1)$ \\
Anchoring point & $42(3.4)$ \\
Bed & $535^{\mathrm{b}}$ \\
Bunk bed & $191(35.7)$ \\
Window & $157(82.2)$ \\
Ceiling & $33(6.2)$ \\
Door/cell bars & $67(12.5)$ \\
Air vent & $68(12.7)$ \\
Shower fixtures & $76(14.2)$ \\
Plumbing & $33(6.2)$ \\
Stair railing & $19(3.6)$ \\
Other & $8(1.5)$ \\
\hline
\end{tabular}

Source: NVDRS, 18 U.S. States, 2003-20I4.

Note. Percentages may not add to $100 \%$ due to rounding. NVDRS = National Violent Death Reporting System.

${ }^{a}$ Number of asphyxia deaths with a specified ligature mechanism. ${ }^{b}$ Number of hanging deaths with a specified ligature anchoring point.

of suicides in our analysis occurred within a month of incarceration, so some decedents' mental health conditions may not have been recognized yet. The resources for mental health evaluations may be limited in correctional facilities, and problems with acquisition and completeness of inmates' prior medical records also may contribute to loss of mental health information, particularly given frequent interfacility transfers (Al-Rousan et al., 2017). Others have emphasized the need for improved suicide risk assessment at intake and other periods of high vulnerability (e.g., around court hearings and facility transfers; Hayes, 2013) and continuity and tracking of care via electronic health records (National Commission on Correctional Health Care, 2017).

Similar issues with substance abuse assessment and access to inmates' previous records, especially for those who died shortly after incarceration, may have resulted in underestimates of substance abuse problems. A 2004 Bureau of Justice Statistics (BJS) survey found that over $50 \%$ of inmates met the Diagnostic and Statistical Manual of Mental Disorders, Fourth Edition, criteria for drug dependence or abuse (Mumola \& Karberg, 2006), and rates of arrest and incarceration for drug offenses have increased over time (Federal Bureau of Investigation, 1996-2006). Although prior substance abuse problems were present more often for incarcerated decedents in this analysis, the percentage $(20.5 \%)$ was lower than BJS estimates. Of note, incarcerated decedents had significantly lower odds of testing positive for substances; however, this may be due to inmates' restricted access 
Table 4. Time Incarcerated by Positive Toxicology Among Incarcerated Suicide Decedents Who Were Tested.

\begin{tabular}{|c|c|c|c|c|}
\hline & Alcohol & Marijuana & Cocaine & Opiates \\
\hline Time Incarcerated & $n(\%)$ & $n(\%)$ & $n(\%)$ & $n(\%)$ \\
\hline \multicolumn{5}{|l|}{ I day or less } \\
\hline Available test result & 133 & 81 & I l2 & 110 \\
\hline Positive test result & $46(34.6)$ & $19(23.5)$ & 13 (I I.6) & $8(7.3)$ \\
\hline \multicolumn{5}{|l|}{2 to 7 days } \\
\hline Available test result & 169 & 95 & 135 & 138 \\
\hline Positive test result & $5(3.0)$ & $18(19.0)$ & $3(2.2)$ & $13(9.4)$ \\
\hline \multicolumn{5}{|l|}{8 days to I month } \\
\hline Available test result & 69 & 37 & 53 & 52 \\
\hline Positive test result & $0(0)$ & $3(8.1)$ & $0(0)$ & $2(3.9)$ \\
\hline \multicolumn{5}{|l|}{31 days to 6 months } \\
\hline Available test result & 61 & 47 & 58 & 58 \\
\hline Positive test result & I (I.6) & $0(0)$ & $0(0)$ & $2(3.4)$ \\
\hline \multicolumn{5}{|c|}{ Recently incarcerated (time unspecified) ${ }^{a}$} \\
\hline Available test result & 43 & 25 & 37 & 37 \\
\hline Positive test result & $6(14.0)$ & I (4.0) & $2(5.4)$ & $2(5.4)$ \\
\hline \multicolumn{5}{|l|}{ More than 6 months } \\
\hline Available test result & 53 & 32 & 47 & 49 \\
\hline Positive test result & I (I.9) & $0(0)$ & $\mathrm{I}(2 . \mathrm{I})$ & $3(6.1)$ \\
\hline \multicolumn{5}{|c|}{ Unknown time incarcerated } \\
\hline Available test result & 889 & 529 & 756 & 757 \\
\hline Positive test result & $42(4.7)$ & $33(6.2)$ & $29(3.8)$ & $68(9.0)$ \\
\hline \multicolumn{5}{|l|}{ Total } \\
\hline Available test result & 1,417 & 846 & 1,198 & 1,201 \\
\hline Positive test result & 101 (7.1) & $74(8.8)$ & $48(4.0)$ & $98(8.2)$ \\
\hline
\end{tabular}

Source: NVDRS, 18 U.S. States, 2003-2014.

Note. Percentages represent the proportion of decedents who tested positive for the substance of those who died within each incarceration period and were tested for the substance. These substance classes represent a selection of the substance classes captured by NVDRS and were selected because often they are used for recreational as opposed to medical purposes. NVDRS = National Violent Death Reporting System.

ancarceration periods described as "recent" in the narrative with no specific amount of time noted, or the decedent was incarcerated for 6 months or less, but the specific amount of time was unknown.

to substances rather than an indication of substance abuse. Altogether, this suggests the importance of early identification of substance use disorders and appropriate treatment (Konrad et al., 2007; WHO, 2007).

\section{Common Circumstances of Incarcerated Decedents}

The current analysis highlights the impact of criminal legal factors on inmate suicide. Hanging was the most common method of suicide for incarcerated decedents, consistent with other findings (Hayes, 2012). Most suicides occurred in a cell, with ligatures made of bedding, attached to beds (mostly bunk beds). Likely, suicides often occur in cells because of the relative privacy and subsequent reduced likelihood of intervention. Although "suicide proof" cells are impossible to create, others have recommended minimizing the use of bunk beds; keeping beds low to the ground; using fully enclosed, solid bed slabs; and minimizing or eliminating potential hanging points in cells (Blaauw et al., 2005; Hayes, 2011; Stone et al., 2017). 
Among incarcerated decedents in this analysis, $16.6 \%$ were housed in single-person cells $(8.2 \%$ were in segregation). Comparatively, approximately $4.4 \%$ of prisoners and $2.7 \%$ of jail inmates are housed in segregation or solitary confinement on an average day (Beck, 2015). Therefore, suicides appear to occur disproportionately among inmates housed in single-person or segregation cells. Isolated housing has an established association with suicide as often it is accompanied by further loss of privileges and uncertainty about the future (e.g., additional disciplinary charges and increased sentence length; Reeves \& Tamburello, 2014). Additionally, those already at increased suicide risk may be more likely to be placed in segregated or single-cell housing; a report published by BJS (Beck, 2015) found that the use of restrictive housing was linked to inmate mental health conditions. Moreover, single-person cells limit the opportunity for other inmates to intervene during a suicide attempt (Reeves \& Tamburello, 2014). Previous housing recommendations include using the least restrictive housing necessary to ensure everyone's safety and generally avoiding restrictive housing for those with serious mental illness (U.S. Department of Justice, 2016).

Incarcerated decedents often disclosed suicidal intent to family, other inmates, and correctional staff. Educating family, inmates, and staff on the process of reporting suicidal disclosures and developing mechanisms to ensure notifications are relayed to appropriate facility personnel may reduce inmate suicide (Hayes, 2013). Additionally, some correctional facilities have implemented inmate peer-to-peer programming to enhance social support and prevent inmate suicide (Bagnall et al., 2015).

Incarcerated decedents who died shortly after incarceration were more likely to have substances in their system than those incarcerated longer. Although this finding likely is a result of decreased access to substances while in custody, it also means that some inmates are intoxicated and/or experiencing symptoms of withdrawal during early periods of incarceration. Substance abuse is associated positively with suicide risk (Harford et al., 2018) over and above mental health conditions like depression (Hawton et al., 2013); substance withdrawal can heighten feelings of depression and anxiety, and intoxication can lower behavioral inhibitions, both of which may exacerbate suicide risk (National Institute on Drug Abuse, 2018; Trevisan et al., 1998). Therefore, withdrawal symptoms may amplify the stress of recent incarceration and increase suicide vulnerability for some inmates (Fagan et al., 2010). Altogether, this suggests the importance of screening and closely monitoring incoming inmates, especially those intoxicated or with known substance abuse problems (Konrad et al., 2007; WHO, 2007), medically appropriate care during withdrawal, and access to substance abuse treatment during incarceration (Fagan et al., 2010; Fiscella et al., 2004).

\section{Study Limitations}

This analysis had several limitations. First, we did not have access to comparison data for the general incarcerated population in the United States. Therefore, we were unable to identify factors that increase suicide risk among all incarcerated persons; instead, we compared incarcerated decedents with suicide decedents in the general population to identify factors unique to this population. Second, we did not have access to data on institutional factors such as facility type (jails, state prisons, federal prisons), security level, public versus private institutions, availability of resources, and policies, all of which may impact inmate suicide and suicide prevention strategies. Third, data for this analysis came from the 18 states participating in NVDRS during the study period; therefore, the data are not nationally representative. Moreover, the number of states included varied over time. ${ }^{1}$ Fourth, NVDRS data are limited to information within source documents. Those investigating inmate deaths may not have access to outside systems or persons with detailed information about decedents, and inside informants' knowledge may be limited due to the nature and length of relationships in correctional settings. Additionally, toxicology data are not collected in a consistent manner across all states, and toxicology testing is not conducted for all decedents. Finally, several variables 
examined are not standard NVDRS data elements; therefore, their availability within source documents and whether abstractors chose to include them in the narrative determined whether they were captured. Consequently, the frequencies of these particular characteristics likely are underestimates.

\section{Implications}

CDC's suicide prevention technical package (Stone et al., 2017) describes several prevention strategies based on the best available evidence and relevant to inmate suicides, including strengthening access to and delivery of suicide care, creating protective environments, and identifying and supporting vulnerable individuals. This resource points to detention facilities as one setting where changing organizational culture to encourage help-seeking and placing more value on mental health could prevent suicide. Based on the current findings, efforts to ensure that inmates with mental health or substance use disorders are identified and receive appropriate services, especially during early and other high stress periods of incarceration, may decrease inmate suicide. Organizational policies that engineer correctional environments to minimize access to common means of suicide also may be effective in reducing these deaths. Suicide prevention training could equip correctional administrators and staff with the skills and resources to create a supportive culture and climate, recognize and respond to signs of suicide, and employ effective suicide prevention measures.

\section{Acknowledgments}

This project was supported in part by an appointment to the Research Participation Program at the Centers for Disease Control and Prevention administered by the Oak Ridge Institute for Science and Education through an interagency agreement between the U.S. Department of Energy and the Centers for Disease Control and Prevention.

\section{Declaration of Conflicting Interests}

The authors declared no potential conflicts of interest with respect to the research, authorship, and/or publication of this article.

\section{Funding}

The authors received no financial support for the research, authorship, and/or publication of this article.

\section{ORCID iD}

Kristiana J. Dixon, PhD (D) https://orcid.org/0000-0002-1841-7360

\section{Notes}

1. In 2003, NVDRS began data collection with six states (Maryland, Massachusetts, New Jersey, Oregon, South Carolina, and Virginia); seven additional states (Alaska, Colorado, Georgia, North Carolina, Oklahoma, Rhode Island, and Wisconsin) joined in 2004, three (Kentucky, New Mexico, and Utah) in 2005, and two (Ohio and Michigan) in 2010. Ohio collected statewide data starting in 2011 and Michigan starting in 2014.

2. Upcoming release was coded anytime the narratives mentioned the decedent being released or a release date (regardless of time), including that the decedent was scheduled or going to be released in the near future (e.g., "the decedent was going to be released soon" or "the decedent's release date was coming up").

3. For incarcerated decedents who disclosed suicidal intent to "other," the first author reviewed and coded the accompanying text using the following categories: cellmate, other inmate, correctional officer, other or unspecified correctional staff (e.g., health care professional), police, and decedent's attorney.

4. In this article, the terms segregation and isolated confinement are used synonymously. 
5. Consistent with the Bureau of Justice Statistics violent crime category, personal crimes were defined as any violent crime perpetrated against another person, including but not limited to domestic violence, homicide, assault, kidnapping, robbery, carjacking, false imprisonment, and violation of a protective/restraining order. Sexual crimes (e.g., rape, sexual assault) were coded separately.

\section{References}

Al-Rousan, T., Rubenstein, L., Sieleni, B., Deol, H., \& Wallace, R. B. (2017). Inside the nation's largest mental health institution: A prevalence study in a state prison system. BMC Public Health, 17, 342. https://doi.org/ 10.1186/s12889-017-4257-0

Bagnall, A. M., South, J., Hulme, C., Woodall, J., Vinall-Collier, K., Raine, G., Kinsella, K., Dixey, R., Harris, L., \& Wright, N. M. J. (2015). A systematic review of the effectiveness and cost-effectiveness of peer education and peer support in prisons. BMC Public Health, 15, 290. https://doi.org/10.1186/s12889-0151584-x

Beck, A. J. (2015). Use of restrictive housing in U.S. prisons and jails, 2011-12 (NCJ 249209). Bureau of Justice Statistics. https://www.bjs.gov/content/pub/pdf/urhuspj1112.pdf

Blaauw, E., Kerkhof, A. J. F. M., \& Hayes, L. M. (2005). Demographic, criminal, and psychiatric factors related to inmate suicide. Suicide and Life-Threatening Behavior, 35(1), 63-75. https://doi.org/10.1521/suli.35.1. 63.59268

Blair, J. M., Fowler, K. A., Jack, S. P., \& Crosby, A. E. (2016). The National Violent Death Reporting System: Overview and future directions. Injury Prevention, 22(Suppl. 1), i6-i11. https://doi.org/10.1136/injuryprev2015-041819

Bronson, J., \& Berzofsky, M. (2017). Indicators of mental health problems reported by prisoners and jail inmates, 2011-12 (NCJ 250612). Bureau of Justice Statistics. https://www.bjs.gov/content/pub/pdf/ imhprpji1112.pdf

Carson, E. A., \& Sabol, W. J. (2016). Aging of the state prison population, 1993-2013 (NCJ 248766). Bureau of Justice Statistics. https://www.bjs.gov/content/pub/pdf/aspp9313.pdf

Centers for Disease Control and Prevention. (2017). Web-based Injury Statistics Query and Reporting System (WISQARS). National Center for Injury Prevention and Control. https://www.cdc.gov/injury/wisqars/fatal. $\mathrm{html}$

Cramer, R. J., Wechsler, H. J., Miller, S. L., \& Yenne, E. (2017). Suicide prevention in correctional settings: Current standards and recommendations for research, prevention, and training. Journal of Correctional Health Care, 23, 313-328. https://doi.org/10.1177/1078345817716162

Fagan, T. J., Cox, J., Helfand, S. J., \& Aufderheide, D. (2010). Self-injurious behavior in correctional settings. Journal of Correctional Health Care, 16, 48-66. https://doi.org/10.1177/1078345809348212

Federal Bureau of Investigation. (1996-2006). Crime in the United States. https://ucr.fbi.gov/ucr-publications

Fiscella, K., Pless, N., Meldrum, S., \& Fiscella, P. (2004). Benign neglect or neglected abuse: Drug and alcohol withdrawal in U.S. jails. Journal of Law, Medicine \& Ethics, 32(1), 129-136. https://doi.org/10.1111/ j.1748-720X.2004.tb00458.x

Harford, T. C., Yi, H., Chen, C. M., \& Grant, B. F. (2018). Substance use disorders and self- and other-directed violence among adults: Results from the National Survey on Drug Use and Health. Journal of Affective Disorders, 225(1), 365-373. https://doi.org/10.1016/j.jad.2017.08.021

Hawton, K., Casañas i Comabella, C., Haw, C., \& Saunders, K. (2013). Risk factors for suicide in individuals with depression: A systematic review. Journal of Affective Disorders, 147(1-3), 17-28. https://doi.org/10. 1016/j.jad.2013.01.004

Hayes, L. M. (2010). National study of jail suicide: 20 years later (Accession number: 024308). National Institute of Corrections. https://nicic.gov/national-study-jail-suicide-20-years-later

Hayes, L. M. (2011). Checklist for the "suicide-resistant" design of correctional facilities. National Center on Institutions and Alternatives. http://www.ncianet.org/wp-content/uploads/2015/05/Checklist-for-the"Suicide-Resistant"-Design-of-Correctional-Facilities.pdf 
Hayes, L. M. (2012). National study of jail suicide: 20 years later. Journal of Correctional Health Care, 18(3), 233-245. https://doi.org/10.1177/1078345812445457

Hayes, L. M. (2013). Suicide prevention in correctional facilities: Reflections and next steps. International Journal of Law and Psychiatry, 36(3-4), 188-194. https://doi.org/10.1016/j.ijlp.2013.04.010

James, D. J., \& Glaze, L. E. (2006). Mental health problems of prison and jail inmates (NCJ 213600). Bureau of Justice Statistics. https://www.bjs.gov/content/pub/pdf/mhppji.pdf

Konrad, N., Daigle, M. S., Daniel, A. E., Dear, G. E., Frottier, P., Hayes, L. M., Kerkhof, A., Liebling, A., \& Sarchiapone, M. (2007). Preventing suicide in prisons, Part I: Recommendations from the International Association for Suicide Prevention Task Force on Suicide in Prison. Crisis, 28(3), 113-121. https://doi.org/ 10.1027/0227-5910.28.3.113

Loeber, R., \& Stallings, R. (2011). Modeling the impact of interventions on local indicators of offending, victimization, and incarceration. In R. Loeber \& D. P. Farrington (Eds.), Young homicide offenders and victims: Risk factors, prediction, and prevention from childhood (pp. 137-152). Springer. https://doi.org/10. 1007/978-1-4419-9949-8_9

Mauer, M., \& King, R. S. (2007). Uneven justice: State rates of incarceration by race and ethnicity. The Sentencing Project. http://www.sentencingproject.org/wp-content/uploads/2016/01/Uneven-Justice-StateRates-of-Incarceration-by-Race-and-Ethnicity.pdf

Mumola, C. J., \& Karberg, J. C. (2006). Drug use and dependence, state and federal prisoners, 2004 (NCJ 213530). Bureau of Justice Statistics. https://www.bjs.gov/content/pub/pdf/dudsfp04.pdf

National Commission on Correctional Health Care. (2017, September 14). National correctional health care providers convene for suicide prevention summit (News release). http://www.corizonhealth.com/down loads/pdf/NCCHC-Provider\%20Suicide\%20Prevention\%20Summit\%2009142017.pdf

National Institute on Drug Abuse. (2018). Commonly abused drugs and withdrawal symptoms. https://www. drugabuse.gov/sites/default/files/nida_commonlyabused_withdrawalsymptoms_10062017-508-1.pdf

Noonan, M. E. (2016a). Mortality in local jails, 2000-2014-statistical tables (NCJ 250169). Bureau of Justice Statistics. https://www.bjs.gov/content/pub/pdf/mlj0014st.pdf

Noonan, M. E. (2016b). Mortality in state prisons, 2001-2014-statistical tables (NCJ 250150). Bureau of Justice Statistics. https:/www.bjs.gov/content/pub/pdf/msp0114st.pdf

Reeves, R., \& Tamburello, A. (2014). Single cells, segregated housing, and suicide in the New Jersey Department of Corrections. Journal of the American Academy of Psychiatry and the Law, 42(4), 484-488. http:// jaapl.org/content/42/4/484.long

Sampson, R. J., \& Laub, J. H. (2003). Life-course desisters? Trajectories of crime among delinquent boys followed to age 70. Criminology, 41(3), 555-592. https://doi.org/10.1111/j.1745-9125.2003.tb00997.x

Snow, L., Paton, J., Oram, C., \& Teers, R. (2002). Self-inflicted deaths during 2001: An analysis of trends. British Journal of Forensic Practice, 4(4), 3-17. https://doi.org/10.1108/14636646200200022

Spohn, C. (2013). Racial disparities in prosecution, sentencing, and punishment. In S. M. Bucerius \& M. Tonry (Eds.) The Oxford handbook of ethnicity, crime, and immigration (pp. 166-193). Oxford University Press.

Stone, D., Holland, K., Bartholow, B., Crosby, A., Davis, S., \& Wilkins, N. (2017). Preventing suicide: A technical package of policies, programs, and practices. Centers for Disease Control and Prevention. https:// doi.org/10.15620/cdc.44275

Trevisan, L. A., Boutros, N., Petrakis, I. L., \& Krystal, J. H. (1998). Complications of alcohol withdrawal: Pathophysiological insights. Alcohol Health and Research World, 22(1), 61-66.

U.S. Department of Justice. (2016). Report and recommendations concerning the use of restrictive housing. https://www.justice.gov/archives/dag/file/815551/download

World Health Organization and International Association for Suicide Prevention. (2007). Preventing suicide in jails and prisons. http://www.who.int/mental_health/prevention/suicide/resource_jails_prisons.pdf 